\title{
How Many Problems Do Family Physicians Manage at Each Encounter? A WReN Study
}

\author{
Jobn W. Beasley, $M D^{1}$ \\ Terry H. Hankey, $M D^{2}$ \\ Rodney Erickson, $M D^{2}$ \\ Kurt C. Stange, $M D, P b D^{3}$ \\ Marlon Mundt, MS \\ Marguerite Elliott, DO \\ Pamela Wiesen, MBA ${ }^{4}$ \\ James Bobula, $P b D^{1}$ \\ 'Department of Family Medicine, University \\ of Wisconsin Medical School, Madison, Wis \\ ${ }^{2}$ Private practice, Madison, Wis \\ ${ }^{3}$ Department of Family Medicine, Case \\ Western Reserve University School of \\ Medicine, Cleveland, Ohio \\ ${ }^{4}$ Wisconsin Research Network (WReN), \\ Madison, Wis
}

Conflicts of interest: none reported

\section{CORRESPONDING AUTHOR}

John W. Beasley, MD

Department of Family Medicine

University of Wisconsin Medical School

777 South Mills Street

Madison, WI 53715

jbeasley@fammed.wisc.edu

\begin{abstract}
PURPOSE The number of problems managed concurrently by family physicians during patient encounters has not been fully explored despite the implications for quality assessment, guideline implementation, education, research, administration, and funding. Our study objective was to determine the number of problems physicians report managing at each visit and compare that with the number reflected in the chart and the bill.
\end{abstract}

METHODS Twenty-nine members of the Wisconsin Research Network reported on encounters with 572 patients using a physician problem log. The patient chart notes and the diagnoses submitted for billing from the encounters were compared with the information in these logs.

RESULTS The physicians reported managing an average of 3.05 problems per encounter and recorded 2.82 in the chart and 1.97 on the bill. For all patients, $37 \%$ of encounters addressed more than 3 problems, and $18 \%$ addressed more than 4 . For patients older than 65 years, there was an average of 3.88 problems at each visit, and for diabetic patients there was an average of 4.60. There was evidence for the selective omission of mental health and substance problems from the diagnoses used for billing.

CONCLUSIONS Family medicine involves the concurrent care of multiple problems, which billing data do not adequately reflect. Our findings suggest a mismatch between family medicine and current approaches to quality assessment, guideline implementation, education, research, administration, and funding. Activities in all these areas need to address the physician's task of prioritizing and integrating care for multiple problems concurrently.

Ann Fam Med 2004;2:405-410. DOI: 10.1370/afm.94.

\section{INTRODUCTION}

$\mathrm{T}$ o measure quality realistically, develop and implement guidelines, educate physicians, design research, and administer and pay for services, it is important to understand the number of problems addressed concurrently during primary care encounters. It is also important to assess whether the commonly used data sources, such as chart review and billing data, adequately reflect this aspect of the complexity of care.

Based on previous work, including that of Flocke et $\mathrm{al}^{1}$ and Zyzanski et $\mathrm{al}_{1}{ }^{2}$ we hypothesized that family physicians manage multiple problems during routine outpatient visits. We further hypothesized that there are considerable differences from what actually occurs during primary care encounters (as measured by physician report), what is recorded in the chart, and what is listed on the bill.

We therefore set out to describe the numbers of problems family physicians report managing during outpatient encounters and compare this number with the number generated from the more standard assessment of the content of the visit; that is, reviewing charts and billing data. This method is somewhat different from that used in direct observation studies, ${ }^{3}$ 
as our study attempted to "get inside the physician's head" to ascertain the problem content of the visit, regardless of whether it was observed or recorded. For example, a physician might see a depressed patient for an acute sprain and assess through the interaction that the patient was doing well on his therapy and make a decision not to explore the problem further or change therapy. Such a patient management action would be captured by physician log but not by direct observation.

\section{METHODS}

We recruited 29 family physician members of the Wisconsin Research Network (WReN) to record the number of discrete problems managed during patient care encounters. Physicians were in both community and academic practices: 9 were in teaching practices and 20 were in community practices of which 12 were rural. The study was reviewed and approved by the University of Wisconsin Human Subjects Committee. Informed consent for patient and physician participation was obtained. Patients were older than 18 years and competent to give informed consent or were accompanied by an adult competent to give consent.

Each physician filled out a problem log for each patient after each encounter with 20 consecutive patients. This log, a copy of the progress note, and a copy of the bill from each of the recorded encounters were mailed to the WReN office.

The progress notes were analyzed by an experienced medical record coder for the number of discrete problems addressed at a level that would justify at least a level one charge.

For purposes of training and standardization, we supplied physicians with detailed instructions, 4 case scenarios, and sample problem logs to fill out. The authors reviewed the responses, and participants were given feedback upon their responses.

For the problem $\log$, a problem was defined as any issue about which the clinician gathered information and made a decision during the encounter. The decision made could be implied (eg, the cough did not require investigation or treatment if it was noted but nothing was done.) To address the issue of when a problem is just part of another problem (eg, neuropathy as part of diabetes), the standard was that if additional data were obtained and a separate decision was made, then the problem should be listed separately. Known problems (eg, diabetes) were not to be listed unless actually addressed at that visit (eg, at an urgent care visit for a sprain). If separate problems merged into 1 at the end of a visit (eg, fever and chest pain merging to pneumonia), then only 1 problem was to be listed.

This broad definition of a problem thus included, eg, fever, hypertension, well-child care, joint pain, or excessive drinking. The definition also included problems in persons other than the patient during the encounter - the so-called secondary patient. ${ }^{4}$ Thus the issue of a husband's depression discussed during a woman's annual examination would be listed as a problem.

For the chart audit, for a problem to be counted, it had to have at least sufficient documentation to justify a level 1 charge. A problem did not have to be listed separately in the progress note for it to be counted; rather, it could have appeared just in the history (eg, "angina is unchanged") with the implication that the decision was not to change therapy if level 1 criteria were otherwise met.

For the audit of the bill, a problem was defined as any problem listed on the bill for that encounter.

To check for the Hawthorne effect (the change in behavior that results from being observed), we reviewed the progress note from the patient's previous visit (prior to the study visit), counted the number of problems, and compared this number with the number in the progress note created at the study visit where the physician was recording the number of problems in the log.

\section{Analysis}

Data were entered into an Access database and analyzed using SAS statistical software. The number of problems recorded in the physician logs, chart audits, and billing data were compared pairwise for statistical significance using the paired $t$ test. Separate $t$ tests of significance were performed for the subgroup of patients who were aged 65 years or older and for the subgroup of patients with diabetes. The chi-square test was used to compare log, chart, and billing data.

\section{RESULTS}

Twenty-nine WReN physicians submitted data on 572 encounters. Eighty-three percent of the encounters were with a regular patient of the physician. Twentyfive percent of the patients were 65 years of age or older, and $62 \%$ were female. These findings are comparable to data from the 2000 National Ambulatory Medical Care Survey (NAMCS), which found for all ambulatory visits that $24.3 \%$ were by patients aged 65 and older and $59.3 \%$ were by female patients. ${ }^{5}$

The main findings of this study for all encounters are presented in Figure 1 and Table 1. Table 1 also includes data for patients older than 65 years and for patients with diabetes.

Of the patients for whom their sex was recorded, the 351 female patients had 3.1 problems per encounter. For the 213 male patients the average number of problems was $2.9(P=.27$, not significant $)$.

When a physician saw his or her regular patients, an average of 3.2 problems were managed at each 


\section{Figure 1. Number of problems per encounter recorded by physician log, patient chart, and bill for 573 encounters.}

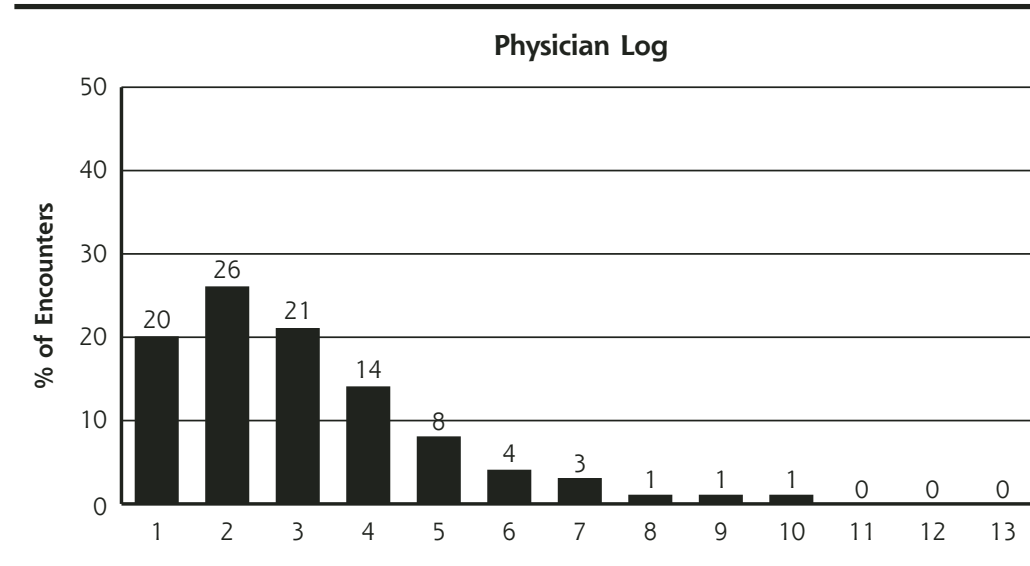

Patient Chart

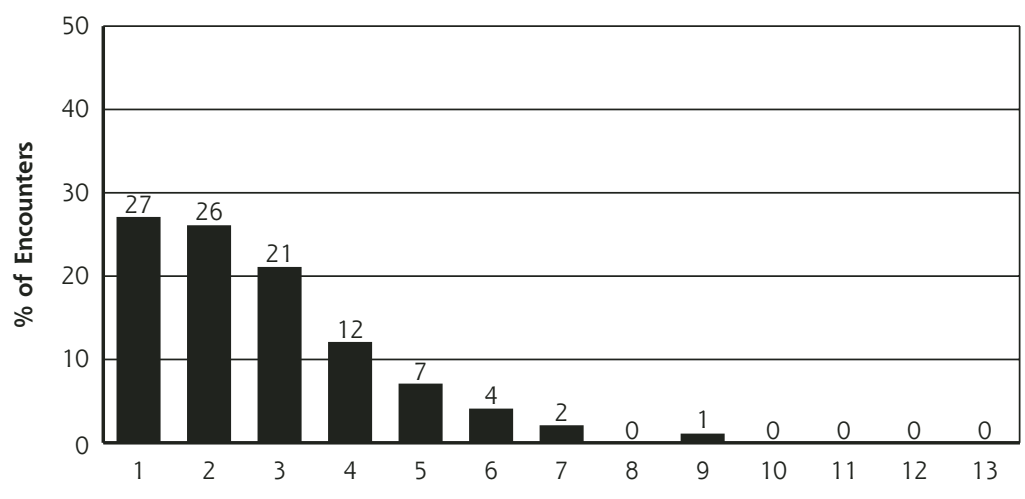

Bill

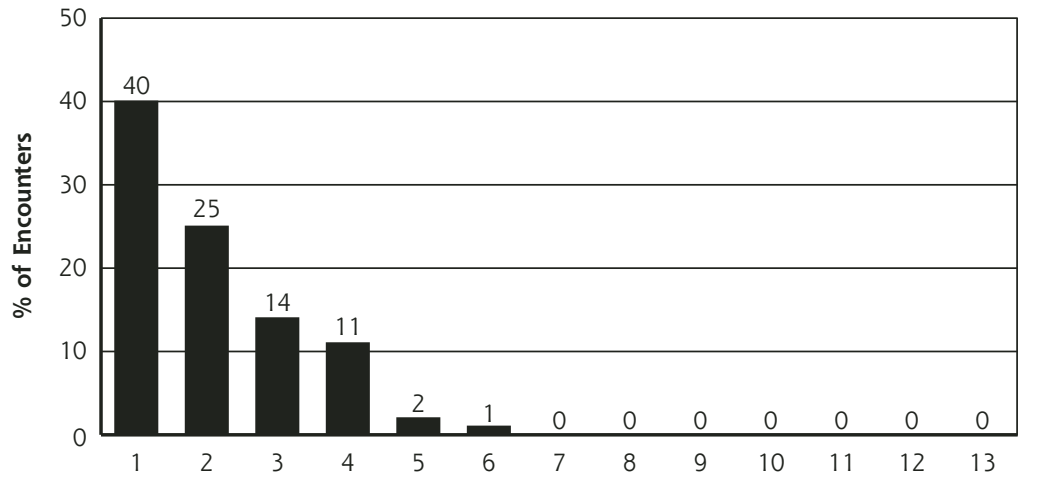

as has been suggested by Susman et al. ${ }^{6}$ The problem logs showed a total of 96 entries related to hypertension, and diagnoses related to hypertension appeared 74 times $(77 \%)$ on the bills. In contrast,137 mental health and substance problems (including tobacco use) were listed in the $\log$, but there were only 58 related diagnoses on the bill (42\%). The difference is significant at $P=.02$.

In checking for the Hawthorne effect, we found that the progress notes from the study encounter averaged 2.82 problems per visit. The notes from the preceding encounter showed only 1.9 problems (SD 1.2) $(P<.001)$.

\section{DISCUSSION}

Our study findings, as have the findings of others exploring the black box of primary care, ${ }^{3}$ have implications for assessing care, implementing guidelines, education, research, administration, and the funding of care. Our study is the first to attempt to assess the content of the primary care encounter by directly asking physicians to record in a log what problems they were addressing and then comparing this information with the usual measurements

Measures of quality applied to primary care physicians may be inappropriate if the quality of care across all patient problems over time is not assessed. Whereas most quality assessment and improvement efforts focus on one problem at a time, ${ }^{7}$ an essential value of primary care is a comprehensive

encounter compared with 2.4 when the patient was not a regular patient of that physician $(P<.001)$.

Physicians reported that $7 \%$ of visits included problems related to a secondary patient. No bill was created for the secondary patient.

We examined 2 categories of problems to test the hypothesis that some problems, especially mental health and substance use and abuse problems, are less likely to appear on the bill than are routine medical problems, approach to identify the most important problem(s) to be dealt with on a given occasion and to prioritize, provide, and integrate care for several problems. ${ }^{8,9}$ Although the definition of primary care by the Institute of Medicine (IOM) includes comprehensiveness, the IOM does not define primary care operationally. ${ }^{10}$ It can, however, be argued that the number of problems addressed during an encounter provides one measure of the comprehensiveness of primary care services. 


\begin{tabular}{|c|c|c|c|}
\hline Encounters & Problem Log & Chart Audit & Bill \\
\hline \multicolumn{4}{|l|}{ All, $n=572$} \\
\hline $\begin{array}{l}\text { Average number of problems per } \\
\text { encounter }( \pm \text { SD) }\end{array}$ & $3.05 \pm 1.9 *$ & $2.82 \pm 1.8^{*}$ & $1.97 \pm 1.2$ \\
\hline Visits with $>3$ problems, $\%$ & 32 & 26 & 14 \\
\hline Visits with $>4$ problems, $\%$ & 18 & 14 & 3 \\
\hline \multicolumn{4}{|l|}{$\begin{array}{l}\text { Subset of patients over age } 65 \mathrm{y} \\
\mathrm{n}=132\end{array}$} \\
\hline $\begin{array}{l}\text { Average number of problems per } \\
\text { encounter }( \pm \text { SD) }\end{array}$ & $3.88 \pm 2.0$ & $3.29 \pm 2.0$ & $2.42 \pm 1.3$ \\
\hline Visits with $>3$ problems, $\%$ & 54 & 41 & 23 \\
\hline Visits with $>4$ problems, $\%$ & 30 & 22 & 5 \\
\hline \multicolumn{4}{|l|}{$\begin{array}{l}\text { Subset of patients with diabetes, } \\
\mathrm{n}=39\end{array}$} \\
\hline $\begin{array}{l}\text { Average number of problems per } \\
\text { encounter }( \pm \text { SD) }\end{array}$ & $4.6 \pm 2.2$ & $3.8 \pm 1.9$ & $2.5 \pm 1.1$ \\
\hline Visits with $>3$ problems, $\%$ & 64 & 54 & 21 \\
\hline Visits with $>4$ problems, $\%$ & 51 & 32 & 3 \\
\hline \multicolumn{4}{|c|}{$\begin{array}{l}\text { Note: Differences between log, chart, and bill for average number of problems are all significant at } P<.001 \text {, } \\
\text { except for those marked by an asterisk. }\end{array}$} \\
\hline
\end{tabular}

have reported discussion of such problems during $18 \%$ of encounters (with no change in billing current procedural terminology [CPT] codes), ${ }_{1}^{14}$ in $16 \%$ to $20 \%$ of encounters, ${ }^{2}$ and in $6 \%$ of office encounters. ${ }^{20}$ In this latter study this care was reflected in only $5 \%$ of the bills for those visits.

Our study, among others, shows that most family medicine outpatient visits involve multiple problems, which is not accurately reflected in the number of diagnoses recorded on the bill. Similarly, Flocke and colleagues found that $58 \%$ of visits had fewer problems on the bill than were observed, with only $13 \%$ having more problems on the bill than were observed. ${ }^{1}$ Other work specifically directed at the diagnoses on the bill showed that only $69 \%$ of

Understanding the concurrent management of problems helps to explain a paradox of primary care. This paradox is the finding that, compared with specialists, generalists tend to provide inferior diseasespecific care ${ }^{11}$ and use fewer resources while producing similar or improved health outcomes for patients with chronic disease, ${ }^{12,13}$ and health care systems that emphasize primary care have better health status among their populations than specialist-dominated systems. ${ }^{14-17}$ The prioritizing and integrating functions of multiproblem management may help explain why.

Our finding of an average of 3.05 problems per encounter is slightly more than what other studies have identified. One early study ${ }^{18}$ found that third-year medical students identified an average of 2.68 problems per logged encounter during the final month of a 12 -week clerkship. During a year-long ambulatory care clerkship, students identified 1.97 problems per encounter with internists as preceptors, 1.32 with family physicians, and 1.21 with pediatricians. ${ }^{19}$ Using direct observation of patient care, Zyzanski et $\mathrm{al}^{2}$ found that physicians in high-volume and low-volume practices identified 1.8 and 1.9 problems per visit, respectively, with problems being defined as the number of diagnoses listed, the number of treatments listed, or a problem mentioned in the assessment or plan. Flocke and colleagues, using direct observation, found an average of 2.7 problems per encounter with family physicians; $24 \%$ of visits had more than 3 , and $14 \%$ had more than 4 problems at each encounter. ${ }^{1}$

Problems involving the secondary patient were identified in $7 \%$ of the encounters in our study. Other studies diagnoses in the progress note appeared on the bill and, conversely, that $22 \%$ of diagnoses listed on the bill were not addressed in the progress note. ${ }^{21}$ Two studies found only $55 \%$ to $57 \%$ concordance between the CPT code on the bill and the content of the visit, with overcoding and undercoding being equally likely. ${ }^{22,23}$

The underreporting in billing may reflect the lack of incentive to report multiple diagnoses when billing for one problem (eg, diabetes) will justify the bill, or when billing for mental health or substance use problems diagnoses pose a risk to the patient. ${ }^{6}$

One other measure of practice content, the National Ambulatory Care Medical Survey (NAMCS) data set, may also be incomplete with respect the number of problems addressed since the entry form for the NAMCS has room for only 3 problems, thus missing problems in up to one third of encounters. Analyses of family medicine based on billings and probably even the NAMCS fail to reflect completely the problem content of encounters.

The management of multiple problems is demanding for physicians. In a study of difficult patients, it was found that the factor of "the patient has many problems" had the second strongest loading of any scale for these patients ${ }^{24}$ and that the existence of (or treatment for) one problem may hinder the care of others. ${ }^{25}$

For this reason, the usefulness of guidelines that focus only on one disease may be limited. Although a reductionistic approach might improve care for the disease under scrutiny, most primary care patients have comorbid conditions for which they consult primary care physicians. ${ }^{26}$ Patients have needs for care of all 
their problems, acute illness or injury, chronic illness, prevention, mental health, and family problems. ${ }^{8}$ Quality improvement efforts that focus on the whole as well as the parts are needed. ${ }^{7}$

Reported shortfalls in following guidelines may be explained in part by the number and types of problems a patient brings to each visit. The competing demands of multiple problems affect mammography screening, ${ }^{27}$ the care of depression, ${ }^{28,29}$ diabetes, ${ }^{30}$ and the provision of informed consent. ${ }^{31,32}$ In the case of counseling for tobacco use, a direct observation study found that in $24 \%$ of encounters with cigarette smokers, the omission of counseling was justified by the nature of the competing problems. ${ }^{33}$ A 1999 review of the literature on issues in guideline implementation shows remarkably few studies addressing the issue of competing demands in guideline implementation. ${ }^{34}$

Our findings and those of related studies have implications for education, in that we need to direct more efforts to the issue of the effective and efficient concurrent management of multiple problems. In the same vein, researchers should not ignore the multiple problem aspect of care in the design of their studies. As a rural physician said to one of the authors $(\mathrm{JB})$, "Don't do research on diabetes. Do research on patients with diabetes!" Research on the management of multiple problems is essential if the results are to be most relevant to family medicine settings. Finally, administrators and funders need to move beyond the assumption that the bill is a reflection of the content of the patient encounter as they assess, support, and pay for patient care.

\section{Limitations}

The most obvious limitation of our study is the dependence on physician self-report. The physicians were aware of the study hypothesis, and they could have exaggerated the number of problems seen at each encounter. Indeed, that would be one hypothesis to explain why the number of problems in the chart at the index visit was higher than the number for preceding visit-an apparent Hawthorne effect. It is also possible, however, that the physicians were simply more careful when writing or dictating their notes after they had listed all the problems they addressed on the encounter problem log. The Hawthorne effect may have increased the number of problems recorded in the patient chart, which would have led us to underestimate the shortfall of the chart in recording the number of problems logged by the physicians.

Although there is room to doubt the accuracy of physician self-report, ${ }^{35}$ we hope that the immediacy of self-report, being no later than the end of the session, would lead to reasonably accurate reporting. In addition, the general concordance or our results with those found in other studies using different methods would suggest that there was no great bias.

An additional limitation of this study relates to reviewing only progress notes. Because other charted information (eg, flow sheets, problem lists, immunization records) was not assessed, we probably missed some problems in the chart audit. The chart audit was further limited because only a single individual reviewed each progress note.

Unfortunately, there is no reference standard for determining the number of problems dealt with at an encounter, as the presence of an observer can influence the process of care ${ }^{36}$ Furthermore, even direct observation studies are limited by the inability to describe those problems that are considered by the physician but do not lead to observable actions. The issue of what problems are addressed in the physician's mind, even if not explicit, is central to understanding this aspect of the complexity of the visit.

Finally, because this study was limited to family physicians in one state, the generalizability is limited.

\section{CONCLUSIONS}

Our study supports the hypothesis that visits to family physicians involve multiple problems, and many visits are complex, with the physician addressing more than 3 problems more than one third of the time. It further supports the hypothesis that the bill is a poor indicator of the actual content of the encounter. These findings, coupled with the findings of others in the literature, suggest a need to reconceptualize our approaches in several areas. First, quality assessment and guidelines should refocus on the entirety of patient care rather than taking a reductionistic look at disease-specific indicators. Second, education for physicians, especially those going into primary care, should move beyond traditional single-disease-oriented educational models. Third, research in family medicine, where appropriate, should address whole-patient issues rather than just single disease issues. Fourth, administrators and funders should pay more attention to the multiproblem nature of care.

Future work should improve on the generalizability of this work, paying special attention to the apparent Hawthorne effect. The work should explore the relationship between the types of problems that the physician actually deals with and the problems that appear on the bill. The work should enable the development of specific plans for improving the assessment of primary care and developing guidelines, for education of current and future physicians, for research protocols that address the entirety of patient care, and for administration and reimbursement mechanisms that support the concurrent care of multiple problems. 
To read or post commentaries in response to this article, see it online at http://www.annfammed.org/cgi/content/full/2/5/405.

Key words: Family medicine; family practice; comprehensive health care; documentation; professional practice; physician's practice patterns; delivery of health care

Portions of this work have been presented at the Wisconsin Research Network (WReN) meeting, Wisconsin Dells, Wis, October 25, 2002, and the National Network Convocation, Silver City, Md, March 22, 2003.

Funding support: Grant and in-kind support were received from the Franciscan Skemp Foundation, the University of Wisconsin Department of Family Medicine, and the Wisconsin Academy of Family Physicians.

Acknowledgments: We thank Ms. Mary Stone for her critically important support of this project.

Study participants: Mary Arenberg, MD; Bruce Barrett, MD; Dennis J. Baumgardner, MD; John W. Beasley, MD; Rod Erickson, MD; Steve Erickson, MD; David Hahn, MD; Terry Hankey, MD; Clark Hanmer, MD; Cynthia Haq, MD; Jim Harrison, MD; Paul Hartlaub, MD; Ira Kastenberg, MD; Rex Kolste, MD; Dean Kresge, MD; Lu Marchand, MD; Mustansir Majeed, MD; James Milford, MD; Lori Neumann, MD; David Olson, MD Scott Peschke, MD; Leon Radant, MD; Joe Ross, MD; Mary Ellen Sabourin, MD; Michael Saunders, MD; George Schroeder, MD; Jean Slane, MD; Jonathan Temte, MD; Lawrence W. Waite, DO

\section{References}

1. Flocke SA, Frank SH, Wenger DA. Addressing multiple problems in the family practice office visit. J Fam Pract. 2001;50:211-216.

2. Zyzanski SJ, Stange KC, Langa D, Flocke SA. Trade-offs in high-volume primary care practice. J Fam Pract. 1998;46:397-402.

3. Stange KC, Zyzanski SJ, Jaen CR, et al. Illuminating the 'black box': a description of 4454 patient visits to 138 family physicians. J Fam Pract. 1998;46:377-389.

4. Flocke SA, Goodwin MA, Stange KC. The effect of a secondary patient on the family practice visit. J Fam Pract. 1998;46:429-434.

5. Cherry DK, Woodwell DA. National Ambulatory Medical Care Survey: 2000 Summary. Advance Data from Vital and Health Statistics. Department of Health and Human Services, Centers for Disease Control and Prevention, National Center for Health Statistics; 2002:328.

6. Susman JL, Crabtree BF, Essink G. Depression in rural family practice: easy to recognize, difficult to diagnose. Arch Fam Med. 1995;4:427-431.

7. Stange KC. The best of times and worst of times. British J Gen Pract. 2001;51:963-966.

8. Stange KC, Jaén CR, Miller WL, Crabtree BF, Flocke SA. The value of a family physician. J Fam Pract. 1998;46:363-368.

9. Stange KC. The paradox of the parts and the whole in understanding and improving general practice. Int J Qual Health Care. 2002; 14:267-268.

10. Donaldson MS, Yourdy KD, Lohr KN, Vanselow NA, eds. Primary Care: America's Health in a New Era. Washington, DC: National Academy Press; 1996.

11. Harrold L, Field T, Gurwitz J. Knowledge, patterns of care, and outcomes of care for generalists and specialists. J Gen Intern Med. 1999;14:499-511.

12. Greenfield S, Nelson EC, Zubkoff M, et al. Variations in resource utilization among medical specialties and systems of care. JAMA. 1992;267:1624-1630.

13. Greenfield S, Rogers W, Mangotich M, Carney MF, Tarlov AR. Outcomes of patients with hypertension and non-insulin-dependent diabetes mellitus treated by different systems and specialties: results from the medical outcomes study. JAMA. 1995;274:1436-1444.
14. Starfield $B$. Is US health care really the best in the world? JAMA. 2000;284:483-485.

15. Starfield B. Primary Care: Balancing Health Needs, Services, and Technology. New York, NY: Oxford University Press; 1998.

16. Starfield B. New paradigms for quality in primary care. $\mathrm{Br} / \mathrm{Gen}$ Pract. 2001;51:303-309.

17. Starfield B. Income inequality, primary care and health indicators. J Fam Pract. 1999;48:275-284.

18. Beasley JW, Makleff R, Myren RW. Evaluating continuity and comprehensiveness of care in an elective family practice clerkship. J Med Educ. 1985;60:320-328.

19. Smith BWH, Eary LE, Ruane TJ, Hough DO. Continuity, family involvement, and clinical content in a year-long ambulatory care clerkship. J Fam Pract. 1989;29:416-421.

20. Orzano AJ, Gregory PM, Nutting PA, Werner JJ, Flocke SA, Stante KC. Care of the secondary patient in family practice: a report from the Ambulatory Sentinel Practice Network. J Fam Pract. 2001;50:113-116.

21. Horner RD, Paris JA, Purvis JR, Lawler FH. Accuracy of patient encounter and billing information in ambulatory care. J Fam Pract. 1991;33:593-598.

22. Chao J, Gillanders WG, Flocke SA, Goodwin MA, Kikano GE, Stange KC. Billing for physician services: a comparison of actual billing with CPT codes assigned by direct observation. J Fam Pract. 1998;47:28-32.

23. Kikano GE, Goodwin MS, Stange KC. Evaluation and management services: a comparison of medical record documentation with actual billing in community family practice. Arch Fam Med. 2000;9:968-971.

24. Schwenk TL, Marquez JT, Lefever RD, Cohen M. Physician and patient determinants of difficult physician-patient relationships. J Fam Pract. 1989;28:59-63.

25. Bayliss EA, Steiner JF, Fernald DH, Crane LA, Main DS. Descriptions of barriers to self-care by persons with comorbid chronic diseases. Ann Fam Med. 2003;1:15-21.

26. Starfield B, Lamke KW, Bernhardt T, Foldes SS, Forrest CB, Weiner JP. Comorbidity: implications for the importance of primary care in 'case' management. Ann Fam Med. 2003;1:8-14.

27. Nutting PA, Baier M, Werner JJ, Cutter G, Conry C, Stewart L. Competing demands in the office visit: what influences mammography recommendations? JABFP. 2001;14:352-361.

28. Rost K, Nutting P, Smith J, Coyne JC, Cooper-Patrick L, Rubenstein $\mathrm{L}$. The role of competing demands in the treatment provided primary care patients with major depression. Arch Fam Med. 2000;9:150-154.

29. Nutting PA, Rost K, Smith J, Werner JJ, Elliot C. Competing demands from physical problems: effect on initiating and completing depression care over 6 months. Arch Fam Med. 2000;9:1059-1064.

30. Brown JB, Harris SB, Webster-Bogaert S, Wetmore S, Faulds C, Stewart $M$. The role of patient, physicians and systemic factors in the management of type 2 diabetes mellitus. Fam Pract. 2002;19:344-349.

31. Braddock $\mathrm{CH}$, Edwards KA, Hasenberg NM, Laidley TL, Levinson W. Informed decision making in outpatient practice: time to get back to basics. JAMA. 1999; 282:2313-2320.

32. Barry MJ. Involving patients in medical decisions: how can physicians do better? JAMA. 1999;282:2356-2357.

33. Jean CR, Mcllvain H, Pol L, Phillips RL, Flocke S, Crabtree B. Tailoring tobacco counseling to the competing demands in the clinical encounter. J Fam Pract. 2001;50:859-863.

34. Cabana MD, Rand CS, Powe NR, et al. Why don't physicians follow clinical practice guidelines? A framework for improvement. JAMA. 1999;282:1458-1465.

35. Montano DE, Phillips WR. Cancer screening by primary care physicians: a comparison of rates obtained from physician self-report, patient survey and chart audit. Am J Pub Health. 1995;85:795-800.

36. Starfield B, Steinwachs D, Morris I, Bause G, Siebert S, Westin C. Presence of observers at patient-practitioner interactions: impact on coordination of care and methodologic implications. Am J Public Health. 1979;69:1021-1025. 